\title{
Conformation of hindered piperidines: Spectroscopic evidence for contribution of boat conformations
}

\author{
A THANGAMANI, J JAYABHARATHI* and A MANIMEKALAI \\ Department of Chemistry, Annamalai University, Annamalainagar 608002 \\ e-mail: jtchalam2005@yahoo.co.in
}

MS received 13 October 2009; revised 10 March 2010; accepted 14 June 2010

\begin{abstract}
High resolution ${ }^{1} \mathrm{H}$ and ${ }^{13} \mathrm{C}$ NMR resonance assignments and conformational assignments were carried out for four $t(3)$-benzyl-r(2), $c(6)$-bis(aryl)piperidin-4-ones 1-4 and their four $N$-nitroso-t(3)benzyl-r(2),c(6)-bis(aryl)piperidin-4-ones 5-8. In addition to conventional 1D NMR methods, 2D shiftcorrelated NMR techniques $\left({ }^{1} \mathrm{H}-{ }^{1} \mathrm{H}\right.$ COSY and ${ }^{1} \mathrm{H}-{ }^{13} \mathrm{C}$ COSY) were used for signal assignments. At room temperature the $t(3)$-benzyl-r(2),c(6)-bis(aryl)piperidin-4-ones 1-4 exist in only one isomeric form whereas their $N$-nitroso derivatives 5-8 exist in two isomeric forms. The preferred conformations of both the isomeric forms of nitrosamines were determined by comparison of the spectral data with those of the corresponding parent amines 1-4 and with the aid of substituent parameters. The results indicate the presence of an equilibrium mixture of boat forms $\mathbf{B}_{1}$ and $\mathbf{B}_{2}$ for $Z$ isomers of 5-8. For the $E$ isomers of 5-8, boat form $B_{1}$ is predicted to be the major conformer. The piperidin-4-ones 1-4 exist in normal chair conformations with equatorial orientations of all the substituents.
\end{abstract}

Keywords. NMR; ${ }^{1} \mathrm{H}$ NMR; ${ }^{13} \mathrm{C}$ NMR; conformational analysis; boat forms.

\section{Introduction}

Many piperidine derivatives are found to possess pharmacological activity and form an essential part of the molecular structure of important drugs. ${ }^{1}$ Most of the piperidine precursors are known to exist in chair conformation. Electron withdrawing groups $(-\mathrm{NO},-\mathrm{CHO},-\mathrm{COR}$ and $-\mathrm{CONHPh})$ introduced at the nitrogen atom profoundly affect the conformations of the heterocyclic rings and orientations of the substituents in 2,6-dialkyl- and 2,6-diaryl- substituted piperidines ${ }^{2-4}$ due to $\mathrm{A}^{1,3}$ strain in the normal chair conformation. The relative preference among the various conformers in the conformational equilibria of $N$-nitroso-r(2),c(6)-diphenylpiperidin-4ones $^{5,6}$ and their derivatives ${ }^{7}$, mono- and di-nitroso$r(2), c(6)$-diphenylhexahydro-1,4-diazepin-5-ones ${ }^{8,9}$, $N$-nitroso-2-phenyl-trans-decahydroquinolin-4-ones ${ }^{10}$ and $\quad N$-nitroso-r(2),c(4)-diaryl-3-azabicyclo[3.3.1] nonan-9-ones ${ }^{11,12}$ have been studied in detail. In all these cases conformations which avoid $\mathrm{A}^{1,3}$ strain are favoured. Literature survey ${ }^{5,6}$ reveals that no systematic work has been done on heavily substituted 2,6-diaryl(di-and tri-substituted phenyl) piperidines

\footnotetext{
*For correspondence
}

having $\mathrm{A}^{1,3}$ strain in the chair conformation. Recently we have synthesized and studied their conformational behaviour of some $N$-nitroso- $t$ (3)-alkyl$r(2), \mathrm{c}(6)$-bis(2'-furyl)piperidin-4-ones and $N$-nitroso$t(3), t(5)$-dimethyl-r(2), c(6)-bis(2'-furyl)piperidin-4one using theoretical and spectral studies. ${ }^{13}$ In the present study, we have chosen a set of compounds in which crowding is increased gradually in the aryl rings attached to 2 and 6 positions of the piperidine ring. The present investigation deals with the synthesis and stereochemical analysis of a set of $t(3)$ benzyl-r(2),c(6)-bis(aryl) piperidin-4-ones 1-4 and their $N$-nitroso derivatives $5-8$ using ${ }^{1} \mathrm{H}$ and ${ }^{13} \mathrm{C}$ NMR spectroscopy and the results are reported here.

\section{Experimental}

\subsection{Preparation of compounds}

The compounds $t(3)$-benzyl-r(2),c(6)-bis(aryl) piperidin-4-ones 1-4 were prepared according to the procedure reported in the literature. ${ }^{14}$ The $N$-nitroso derivatives 5-8 were prepared from 1-4 by adopting the general procedure described in the literature. ${ }^{5}$ All the $N$-nitroso derivatives 5-8 were purified by column chromatography using benzene: ethyl ace- 
tate $(4: 1)$ as eluent. The yields are as follows: $80 \%$ (1); 78\% (2); 70\% (3); 60\% (4); 85\% (5); 80\% (6); $75 \%(7) ; 70 \%(8)$ and the melting points are as follows: semisolid (1); $83^{\circ} \mathrm{C} \mathrm{(2);} 130^{\circ} \mathrm{C} \mathrm{(3);8} 81^{\circ} \mathrm{C} \mathrm{(4)}$; $166^{\circ} \mathrm{C}(5)$; semisolid (6); semisolid (7) and semisolid (8).

\subsection{Recording of spectra}

${ }^{1} \mathrm{H}$ and ${ }^{13} \mathrm{C}$ NMR spectra were recorded on a Bruker DRX 500 NMR spectrometer operating at 500.03 and $125.75 \mathrm{MHz}$ for ${ }^{1} \mathrm{H}$ and ${ }^{13} \mathrm{C}$, respectively. Solutions were prepared by dissolving $10 \mathrm{mg}\left({ }^{1} \mathrm{H}\right)$ and $50 \mathrm{mg}\left({ }^{13} \mathrm{C}\right)$ of the compound in $0.5 \mathrm{ml}$ of the solvent $\left(\mathrm{CDCl}_{3}\right)$. All NMR measurements were made on $5 \mathrm{~mm}$ NMR tubes. The spectral parameters for ${ }^{1} \mathrm{H}$ were as follows: spectral width $6009.615 \mathrm{~Hz}$, acquisition time $2.726 \mathrm{~s}$, number of data points 32768 , digital resolution $0 \cdot 3 \mathrm{~Hz}$ and number of scans 32 . For ${ }^{13} \mathrm{C}$ the spectral parameters were as follows: spectral width $27777.777 \mathrm{~Hz}$, acquisition time $0.295 \mathrm{~s}$, number of data points 16384 , digital resolution $10.0 \mathrm{~Hz}$ and number of scans 64 . The phase sensitive of ${ }^{1} \mathrm{H}-{ }^{1} \mathrm{H}$ COSY and ${ }^{1} \mathrm{H}-{ }^{13} \mathrm{C}$ COSY spectra were recorded on a Bruker DRX 500 NMR spectrometer using standard parameters. For ${ }^{1} \mathrm{H}-{ }^{1} \mathrm{H}$ COSY, spectral width $6666.667 \mathrm{~Hz}$, acquisition time $0 \cdot 154 \mathrm{~s}$, number of data points 2048 and number of scans 16. For ${ }^{1} \mathrm{H}-{ }^{13} \mathrm{C}$ COSY, spectral width $6009.615 \mathrm{~Hz}$, acquisition time $0.085 \mathrm{~s}$, number of data points 1024 and number of scans 16

\section{Results and discussion}

The high resolution ${ }^{1} \mathrm{H}$ and ${ }^{13} \mathrm{C}$ NMR spectra of $t(3)$ benzyl-r(2),c(6)-bis(4-methylphenyl)-piperidin-4-one (1), $t$ (3)-benzyl-r(2), $c(6)$-bis(4-methoxyphenyl)piperidin-4-one (2), $t(3)$-benzyl-r(2),c(6)-bis(3,4-dimethoxyphenyl)piperidin-4-one (3), $t(3)$-benzyl$r(2), c(6)-b i s(3, \quad 4, \quad 5$-trimethoxyphenyl)-piperidin4-one (4), $\quad N$-nitroso-t(3)-benzyl-r(2),c(6)-bis (4-methylphenyl)piperidin-4-one (5), $N$-nitroso-t(3)benzyl-r(2), c(6)-bis(4-methoxy-phenyl)piperidin-4one (6), $N$-nitroso-t(3)-benzyl-r(2),c(6)-bis(3, 4dimethoxyphenyl)-piperidin-4-one (7) and $\mathrm{N}$ nitroso-t(3)-benzyl-r(2),c(6)-bis(3,4,5-trimethoxyphenyl)-piperidin-4-one (8) (scheme 1) have been recorded in $\mathrm{CDCl}_{3}$ and analysed. The ${ }^{1} \mathrm{H}$ NMR spectra of $\mathrm{N}$-nitroso derivatives 5-8 contained two distinct signals for each $\alpha$ proton at room temperature. ${ }^{13} \mathrm{C}$ NMR spectra also reveal the presence of two sets of signals. The observation of two sets of signals in 5-8 suggests the presence of restricted rotation around $\mathrm{N}-\mathrm{NO}$ bond and establishment of equilibrium between two rotamers with coplanar orientations of nitroso group in these derivatives. The two rotamers are labelled as $\mathbf{Z}$ (nitroso oxygen is syn to benzylic group at $\mathbf{C}-3$ ) and $\mathbf{E}$ (nitroso oxygen is anti to benzylic group at $\mathrm{C}-3$ ) isomers (figure 1).

The assignment of proton signals in the two isomers was done based on the results obtained in the ${ }^{1} \mathrm{H}-{ }^{1} \mathrm{H}$ COSY spectra. Literature reveals ${ }^{5,6}$ that $\operatorname{syn} \alpha$ protons should be deshielded to a lesser extent than anti $\alpha$ protons. Therefore $\mathrm{H}(2)$ is expected to resonate at lower frequency in the $\mathbf{Z}$ isomer relative to the $\mathbf{E}$ isomer. Based on this among the two sets of signals the set in which $\mathrm{H}(2)$ is considerably lower can be assigned to the $\mathbf{Z}$ isomer. In ${ }^{13} \mathrm{C}$ NMR spectra the two sets of signals can be easily differentiated

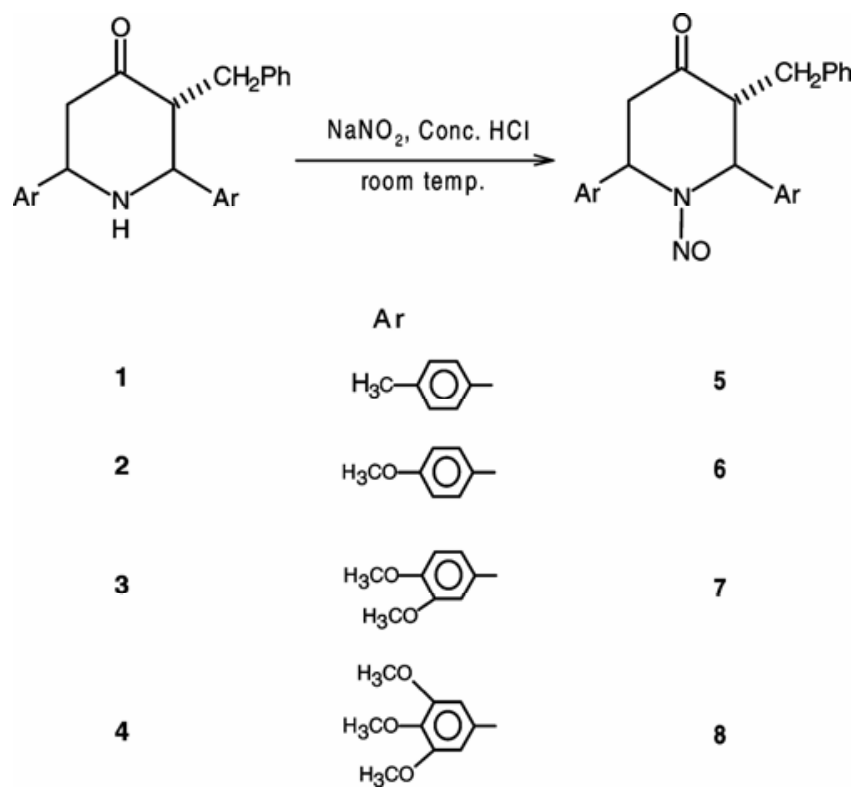

Scheme 1. Structure of compounds 1-8.

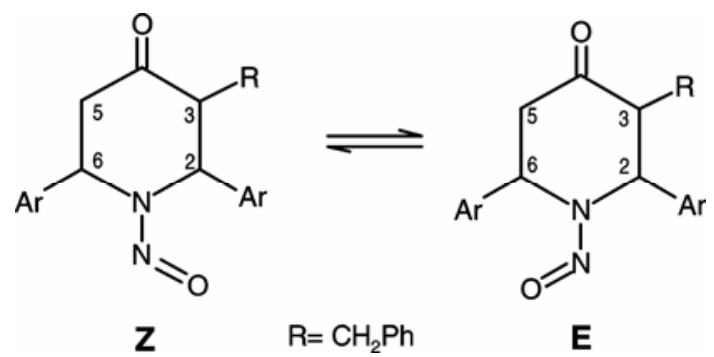

Figure 1. Equilibrium involving syn and anti rotamers. 
Table 1. ${ }^{1} \mathrm{H}$ chemical shifts (ppm) and coupling constant (Hz) 1-8.

\begin{tabular}{|c|c|c|c|c|c|c|c|c|}
\hline & mp. & . $H(2)$ & $\mathrm{H}(3)$ & $\mathrm{H}(5)$ & $\mathrm{H}(6)$ & $\mathrm{CH}_{2} \mathrm{Ph}$ & Others & $\begin{array}{c}\text { Aromatic } \\
\text { protons }\end{array}$ \\
\hline 1 & & $\begin{array}{l}3 \cdot 64 \\
(d, 9 \cdot 9 \mathrm{~Hz})\end{array}$ & $\begin{array}{l}2 \cdot 93-3 \cdot 04 \\
(m)\end{array}$ & $\begin{array}{l}2 \cdot 59(a x)(t, 12 \cdot 0 \mathrm{~Hz}) \\
2 \cdot 41(e q)(d d, 12 \cdot 6,2 \cdot 9 \mathrm{~Hz})\end{array}$ & $\begin{array}{l}3 \cdot 94 \\
(d d, 11 \cdot 3,2 \cdot 7 \mathrm{~Hz})\end{array}$ & $\begin{array}{l}2 \cdot 93-3 \cdot 04(m) \\
2 \cdot 30(m)\end{array}$ & $\begin{array}{l}2 \cdot 26 \\
2 \cdot 31\end{array}$ & $\begin{array}{l}6 \cdot 95-7 \cdot 17 \\
7 \cdot 22-7 \cdot 32\end{array}$ \\
\hline 2 & & $\begin{array}{l}3 \cdot 70 \\
(d, 10 \cdot 0 \mathrm{~Hz})\end{array}$ & $\begin{array}{l}2 \cdot 95-3 \cdot 07 \\
(m)\end{array}$ & $\begin{array}{l}2 \cdot 68(a x)(t, 12 \cdot 1 \mathrm{~Hz}) \\
2 \cdot 55(e q)(d d, 12 \cdot 7,2 \cdot 9 \mathrm{~Hz})\end{array}$ & $\begin{array}{l}4 \cdot 01 \\
(d d, 11 \cdot 5,2 \cdot 6 \mathrm{~Hz})\end{array}$ & $\begin{array}{l}2 \cdot 95-3 \cdot 07(m) \\
2 \cdot 30(d, 12 \cdot 9 \mathrm{~Hz})\end{array}$ & $\begin{array}{l}3 \cdot 77 \\
3 \cdot 82\end{array}$ & $\begin{array}{l}6 \cdot 84-7 \cdot 09 \\
7 \cdot 13-7 \cdot 25 \\
7 \cdot 27-7.48\end{array}$ \\
\hline 3 & & $\begin{array}{l}3 \cdot 71 \\
(d, 10 \cdot 3 \mathrm{~Hz})\end{array}$ & $3 \cdot 01(t)$ & $\begin{array}{l}2 \cdot 72(a x)(t, 12 \cdot 0 \mathrm{~Hz}) \\
2 \cdot 60(e q)(d d, 12 \cdot 8,2 \cdot 9 \mathrm{~Hz})\end{array}$ & $\begin{array}{l}4 \cdot 03 \\
(d d, 11 \cdot 5,2 \cdot 8 \mathrm{~Hz})\end{array}$ & $\begin{array}{l}3 \cdot 09(d d, 13 \cdot 5,8 \cdot 7 \mathrm{~Hz}) \\
2 \cdot 32(d d, 13 \cdot 8 \mathrm{~Hz})\end{array}$ & $\begin{array}{l}3 \cdot 86 \\
3 \cdot 88 \\
3 \cdot 89 \\
3 \cdot 90\end{array}$ & $\begin{array}{l}6 \cdot 81-6 \cdot 88 \\
6 \cdot 95-7 \cdot 09 \\
7 \cdot 10-7 \cdot 16\end{array}$ \\
\hline 4 & & $\begin{array}{l}3 \cdot 69 \\
(d, 10 \cdot 4 \mathrm{~Hz})\end{array}$ & $\begin{array}{l}3 \cdot 00-3 \cdot 02 \\
(m)\end{array}$ & $\begin{array}{l}2 \cdot 72(a x)(t, 12 \cdot 0 \mathrm{~Hz}) \\
2 \cdot 63(e q)(d d, 13 \cdot 0,3 \cdot 0 \mathrm{~Hz})\end{array}$ & $\begin{array}{l}4 \cdot 01 \\
(d d, 11 \cdot 4,2 \cdot 6 \mathrm{~Hz})\end{array}$ & $\begin{array}{l}3 \cdot 14(d d, 13 \cdot 8,8 \cdot 2 \mathrm{~Hz}) \\
2 \cdot 35(d d, 13 \cdot 6,2 \cdot 4 \mathrm{~Hz})\end{array}$ & $\begin{array}{l}3 \cdot 82 \\
3 \cdot 85 \\
3 \cdot 86\end{array}$ & $\begin{array}{l}6 \cdot 66,6 \cdot 67 \\
6 \cdot 75-7 \cdot 17\end{array}$ \\
\hline 5 & $\mathbf{E}$ & $\begin{array}{l}6 \cdot 23 \\
(d, 1 \cdot 6 \mathrm{~Hz})\end{array}$ & $\begin{array}{l}3 \cdot 59 \\
(m)\end{array}$ & $\begin{array}{l}2 \cdot 93(d d, 17 \cdot 2,10 \cdot 3 \mathrm{~Hz}) \\
2 \cdot 75(d d, 17 \cdot 2,6 \cdot 2 \mathrm{~Hz})\end{array}$ & $\begin{array}{l}5 \cdot 68 \\
(d d, 10 \cdot 3,6 \cdot 2 \mathrm{~Hz})\end{array}$ & $\begin{array}{l}3 \cdot 10(d d, 13 \cdot 9,4 \cdot 2 \mathrm{~Hz}) \\
2 \cdot 63(d d, 13 \cdot 9,10 \cdot 7 \mathrm{~Hz})\end{array}$ & $\begin{array}{l}2 \cdot 23 \\
2 \cdot 33\end{array}$ & $\begin{array}{l}6 \cdot 68-6 \cdot 71 \\
6 \cdot 89-6 \cdot 95\end{array}$ \\
\hline & $\mathbf{Z}$ & $\begin{array}{l}5 \cdot 97 \\
(d, 5 \cdot 9 \mathrm{~Hz})\end{array}$ & $\begin{array}{l}3 \cdot 38 \\
(m)\end{array}$ & $\begin{array}{l}3 \cdot 34(d d, 5 \cdot 3 \mathrm{~Hz}) \\
3 \cdot 03(d d, 17 \cdot 5,6 \cdot 6 \mathrm{~Hz})\end{array}$ & $\begin{array}{l}6 \cdot 34 \\
(t, 11 \cdot 9 \mathrm{~Hz})^{*}\end{array}$ & $\begin{array}{l}2 \cdot 84(d d, 13 \cdot 9,5 \cdot 7 \mathrm{~Hz}) \\
2 \cdot 68(d d, 14 \cdot 0,7 \cdot 3 \mathrm{~Hz})\end{array}$ & $\begin{array}{l}2 \cdot 22 \\
2 \cdot 32\end{array}$ & $\begin{array}{l}7 \cdot 03-7 \cdot 14 \\
7 \cdot 18-7 \cdot 32\end{array}$ \\
\hline 6 & $\mathbf{E}$ & $\begin{array}{l}6 \cdot 19 \\
(d, 1 \cdot 3 \mathrm{~Hz})\end{array}$ & $3 \cdot 57(m)$ & $\begin{array}{l}2.95(d d, 17 \cdot 1,9 \cdot 5 \mathrm{~Hz}) \\
2 \cdot 77(d d, 17 \cdot 1,6.5 \mathrm{~Hz})\end{array}$ & $\begin{array}{l}5 \cdot 78 \\
(d d, 9 \cdot 2,6 \cdot 7 \mathrm{~Hz})\end{array}$ & $\begin{array}{l}2 \cdot 66(d d, 13 \cdot 8,10 \cdot 6 \mathrm{~Hz}) \\
3 \cdot 05-3 \cdot 11(\mathrm{~m}, 4 \cdot 3 \mathrm{~Hz})\end{array}$ & $\begin{array}{r}3 \cdot 70 \\
3 \cdot 78\end{array}$ & $\begin{array}{l}6 \cdot 58-6 \cdot 64 \\
6 \cdot 70-6 \cdot 83\end{array}$ \\
\hline & $\mathbf{Z}$ & $\begin{array}{l}5 \cdot 97 \\
(d, 5 \cdot 9 \mathrm{~Hz})\end{array}$ & $\begin{array}{l}3 \cdot 32-3 \cdot 38 \\
(m)\end{array}$ & $\begin{array}{l}3 \cdot 32-3 \cdot 38(\mathrm{~m}, 4 \cdot 5 \mathrm{~Hz}) \\
3 \cdot 05-3 \cdot 11(\mathrm{~m}, 6 \cdot 9 \mathrm{~Hz})\end{array}$ & $\begin{array}{l}6 \cdot 37 \\
(t, 11 \cdot 1 \mathrm{~Hz})^{*}\end{array}$ & $\begin{array}{l}2 \cdot 69(d d, 14 \cdot 2,7 \cdot 3 \mathrm{~Hz}) \\
2 \cdot 83(d d, 13 \cdot 9,5 \cdot 7 \mathrm{~Hz})\end{array}$ & $\begin{array}{l}3 \cdot 70 \\
3 \cdot 77\end{array}$ & $\begin{array}{l}7 \cdot 03-7 \cdot 10 \\
7 \cdot 17-7 \cdot 32\end{array}$ \\
\hline 7 & $\mathbf{E}$ & $\begin{array}{l}6 \cdot 21 \\
(d, 1 \cdot 9 \mathrm{~Hz})\end{array}$ & $\begin{array}{l}3 \cdot 58-3 \cdot 61 \\
(m)\end{array}$ & $\begin{array}{l}3 \cdot 01(d d, 17 \cdot 2,9 \cdot 6 \mathrm{~Hz}) \\
2 \cdot 80(d d, 17 \cdot 2,6 \cdot 5 \mathrm{~Hz})\end{array}$ & $\begin{array}{l}5 \cdot 80 \\
(d d, 9 \cdot 5,6 \cdot 6 \mathrm{~Hz})\end{array}$ & $\begin{array}{l}3 \cdot 09-3 \cdot 14(m) \\
2 \cdot 65(d d, 13 \cdot 9,10 \cdot 7 \mathrm{~Hz})\end{array}$ & $\begin{array}{r}3 \cdot 58 \\
3 \cdot 66\end{array}$ & $\begin{array}{l}6 \cdot 49-6 \cdot 54 \\
6 \cdot 58-6 \cdot 64\end{array}$ \\
\hline & $\mathbf{Z}$ & $\begin{array}{l}5 \cdot 96 \\
(d, 6 \cdot 2 \mathrm{~Hz})\end{array}$ & $\begin{array}{l}3 \cdot 36-3 \cdot 41 \\
(m)\end{array}$ & $\begin{array}{l}3 \cdot 36-3 \cdot 41(\mathrm{~m}, 4 \cdot 2 \mathrm{~Hz}) \\
3 \cdot 09-3 \cdot 14(\mathrm{~m})\end{array}$ & $\begin{array}{l}6 \cdot 41 \\
(d d, 6 \cdot 7,4 \cdot 3 \mathrm{~Hz})\end{array}$ & $\begin{array}{l}2 \cdot 84(d d, 13 \cdot 9,5 \cdot 7 \mathrm{~Hz}) \\
2 \cdot 68(d d, 14 \cdot 2,6 \cdot 8 \mathrm{~Hz})\end{array}$ & $\begin{array}{l}3 \cdot 71 \\
3 \cdot 78 \\
3 \cdot 84 \\
3 \cdot 94 \\
3 \cdot 96\end{array}$ & $\begin{array}{l}6 \cdot 73-6 \cdot 83 \\
6 \cdot 97-7 \cdot 03 \\
7 \cdot 19-7.41\end{array}$ \\
\hline 8 & $\mathbf{E}$ & $6 \cdot 23(s)$ & $\begin{array}{l}3 \cdot 57-3 \cdot 61 \\
(m)\end{array}$ & $\begin{array}{l}3 \cdot 03(d d, 17 \cdot 0,8 \cdot 5 \mathrm{~Hz}) \\
2 \cdot 87(d d, 17 \cdot 1,6 \cdot 8 \mathrm{~Hz})\end{array}$ & $\begin{array}{l}5 \cdot 94 \\
(t, 15 \cdot 2 \mathrm{~Hz})^{*}\end{array}$ & $\begin{array}{l}3 \cdot 12(d d, 13 \cdot 9,4 \cdot 6 \mathrm{~Hz}) \\
2 \cdot 65-2 \cdot 71(\mathrm{~m})\end{array}$ & $\begin{array}{l}3 \cdot 62 \\
3 \cdot 63\end{array}$ & $\begin{array}{l}7 \cdot 05,7 \cdot 07 \\
7 \cdot 21-7 \cdot 29\end{array}$ \\
\hline & $\mathbf{Z}$ & $\begin{array}{l}6 \cdot 13 \\
(d, 4 \cdot 9 \mathrm{~Hz})\end{array}$ & $\begin{array}{l}3 \cdot 42 \\
(d d)\end{array}$ & $\begin{array}{l}3 \cdot 36(d d, 16 \cdot 9,3 \cdot 6 \mathrm{~Hz}) \\
3 \cdot 20(d d, 16 \cdot 9,7 \cdot 2 \mathrm{~Hz})\end{array}$ & $6 \cdot 45(s)$ & $\begin{array}{l}2 \cdot 93(d d, 13 \cdot 9,5 \cdot 8 \mathrm{~Hz}) \\
2 \cdot 65-2 \cdot 71(\mathrm{~m})\end{array}$ & $\begin{array}{l}3 \cdot 68 \\
3 \cdot 71 \\
3 \cdot 72 \\
3 \cdot 74 \\
3 \cdot 77\end{array}$ & $7 \cdot 33-7 \cdot 35$ \\
\hline
\end{tabular}

*Total width derived from $\mathrm{H}(6)$ signal

based on intensities. Literature study reveals ${ }^{3,5,6}$ that syn $\alpha$ carbons should be shielded to a greater extent than anti $\alpha$ carbons. Therefore $\mathrm{C}(2)$ should absorb at higher frequency in the $\mathbf{E}$ isomer than in the $\mathbf{Z}$ isomer. Among the two sets of signals for the $\mathbf{E}$ and $\mathbf{Z}$ isomers the one in which $\mathrm{C}(2)$ is considerably higher is assigned to the $\mathbf{E}$ isomer. This assignment is further confirmed by recording ${ }^{1} \mathrm{H}-{ }^{13} \mathrm{C}$ COSY spectra for 5-8. The chemical shifts and coupling constants derived from ${ }^{1} \mathrm{H}$ NMR spectra are displayed in table 1. Table 2 reports ${ }^{13} \mathrm{C}$ chemical shifts of $\mathbf{1 - 8}$ recorded at room temperature.

\subsection{Ring conformations}

3.1a 3-Benzylpiperidin-4-ones 1-4: The observation of one large $(\approx 11 \mathrm{~Hz})$ and one small coupling $(\approx 3 \mathrm{~Hz}$ ) about $\mathrm{C}(5)-\mathrm{C}(6)$ bond and one large coupling $(\approx 10 \mathrm{~Hz})$ about $\mathrm{C}(2)-\mathrm{C}(3)$ bond in piperidin-4-ones 1-4 reveals that these compounds adopt normal chair conformations with equatorial orientation of aryl rings at C-2 and C-6 and benzylic group at C-3 .

3.1b N-nitroso-3-benzylpiperidin-4-ones 5-8: The coupling constants about $\mathbf{C}(2)-\mathbf{C}(3)$ bond in the $\mathbf{Z}$ 
Table 2. ${ }^{13} \mathrm{C}$ Chemical shifts of $\mathbf{1 - 8}$.

\begin{tabular}{|c|c|c|c|c|c|c|c|c|c|}
\hline \multicolumn{2}{|c|}{ Compound } & $\mathrm{C}(2)$ & $\mathrm{C}(3)$ & $\mathrm{C}(4)$ & $C(5)$ & $\mathrm{C}(6)$ & $\mathrm{CH}_{2} \mathrm{Ph}$ & Others & Aromatic carbons \\
\hline \multicolumn{2}{|l|}{1} & $66 \cdot 97$ & $59 \cdot 50$ & $208 \cdot 10$ & $51 \cdot 40$ & $61 \cdot 45$ & $30 \cdot 27$ & $\begin{array}{l}20 \cdot 98 \\
20 \cdot 92\end{array}$ & $141 \cdot 06-125 \cdot 39$ \\
\hline \multicolumn{2}{|l|}{2} & $66 \cdot 47$ & 59.50 & $208 \cdot 03$ & $51 \cdot 30$ & $60 \cdot 93$ & $30 \cdot 17$ & 54.92 & $159 \cdot 16-113 \cdot 70$ \\
\hline \multicolumn{2}{|l|}{3} & $67 \cdot 26$ & $59 \cdot 80$ & $208 \cdot 34$ & $51 \cdot 60$ & 61.62 & $30 \cdot 38$ & 55.96 & $149 \cdot 18-109 \cdot 78$ \\
\hline \multicolumn{2}{|l|}{4} & $67 \cdot 31$ & $60 \cdot 24$ & $207 \cdot 43$ & $50 \cdot 86$ & 61.57 & $29 \cdot 97$ & $\begin{array}{l}55.63 \\
58.95\end{array}$ & $152 \cdot 80-103 \cdot 12$ \\
\hline \multirow[t]{2}{*}{5} & $\mathbf{E}$ & $61 \cdot 80$ & 52.52 & $207 \cdot 28$ & $43 \cdot 48$ & 55.07 & $35 \cdot 69$ & $\begin{array}{l}20 \cdot 83 \\
20 \cdot 89\end{array}$ & $138 \cdot 35-126 \cdot 21$ \\
\hline & $\mathbf{Z}$ & 55.49 & $53 \cdot 13$ & $207 \cdot 06$ & $42 \cdot 39$ & $60 \cdot 22$ & $34 \cdot 59$ & & \\
\hline \multirow[t]{2}{*}{6} & $\mathbf{E}$ & 61.49 & 52.93 & $207 \cdot 00$ & $42 \cdot 71$ & $54 \cdot 68$ & $35 \cdot 33$ & $\begin{array}{l}54 \cdot 68 \\
54 \cdot 83\end{array}$ & $159 \cdot 08-113 \cdot 21$ \\
\hline & $\mathbf{Z}$ & $54 \cdot 83$ & $53 \cdot 70$ & $206 \cdot 77$ & $41 \cdot 76$ & $59 \cdot 60$ & $34 \cdot 26$ & & \\
\hline \multirow[t]{2}{*}{7} & $\mathbf{E}$ & $61 \cdot 62$ & $52 \cdot 64$ & $206 \cdot 61$ & $42 \cdot 29$ & $54 \cdot 79$ & $35 \cdot 14$ & $\begin{array}{l}55 \cdot 12 \\
55 \cdot 23\end{array}$ & $153 \cdot 75-108 \cdot 39$ \\
\hline & $\mathbf{Z}$ & $55 \cdot 37$ & $53 \cdot 66$ & $206 \cdot 41$ & $41 \cdot 37$ & $59 \cdot 66$ & 33.84 & $\begin{array}{l}54 \cdot 95 \\
55 \cdot 05\end{array}$ & \\
\hline \multirow[t]{2}{*}{8} & $\mathbf{E}$ & $62 \cdot 24$ & $52 \cdot 61$ & $206 \cdot 93$ & $42 \cdot 07$ & $53 \cdot 72$ & $35 \cdot 69$ & $\begin{array}{l}55 \cdot 38 \\
55 \cdot 67\end{array}$ & $152 \cdot 86-103 \cdot 24$ \\
\hline & $\mathbf{Z}$ & 54.91 & $53 \cdot 14$ & $206 \cdot 93$ & $41 \cdot 30$ & $60 \cdot 48$ & $34 \cdot 84$ & & \\
\hline
\end{tabular}
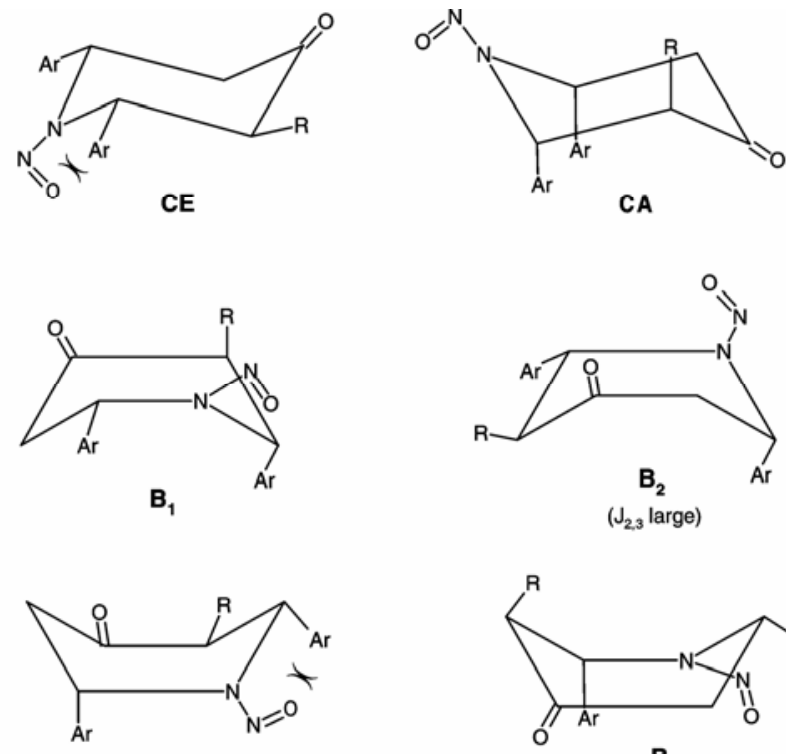

$\mathbf{B}_{3}$

$\left(\mathrm{J}_{2,3}\right.$ large $)$

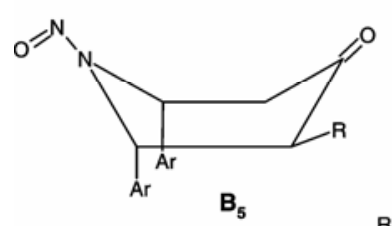

$\mathrm{R}=\mathrm{CH}_{2} \mathrm{Ph}$

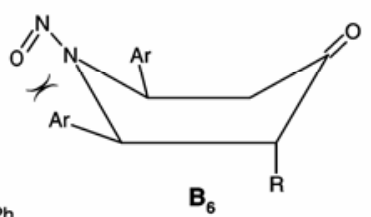

$\mathrm{Ar}=\mathrm{Ph}$

Scheme 2. Possible conformation of the $\mathbf{Z}$-isomers of 5-8. isomers of $N$-nitroso-3-benzyl derivatives 5-8 are in the range of $4.9-6 \cdot 2 \mathrm{~Hz}$. The two couplings observed about $\mathrm{C}(5)-\mathrm{C}(6)$ bond are in the range of $6 \cdot 6-7 \cdot 2$ and $3.6-5 \cdot 3 \mathrm{~Hz}$. The coupling constants are in contrast to the values observed in piperidin-4-ones 1-4 which exist in normal chair conformation with equatorial orientation of all the substituents. In the normal chair conformation severe pseudo allylic $\left(\mathrm{A}^{1,3}\right)$ strain exists between $N$-nitroso group and equatorial aryl rings at $\mathrm{C}-2$ and $\mathrm{C}-6$ in $\mathbf{5 - 8}$. In order to relieve $\mathrm{A}^{1,3}$ strain, the $N$-nitroso derivatives 5-8 may adopt alternate chair form or boat form. The possible conformations for the $\mathbf{Z}$ isomers of 5-8 are shown in scheme 2.

In conformations $\mathbf{C E}, \mathbf{B}_{3}$ and $\mathbf{B}_{6}$ shown in scheme 2 , allylic strain exists between $\mathrm{N}-\mathrm{N}=\mathrm{O}$ group and aryl ring and hence these conformations are ruled out in the present study. Moreover, in the conformations $\mathbf{B}_{3}$ and $\mathbf{C E}, J_{2,3}$ is expected to be around $10-12 \mathrm{~Hz}$ which is in contrast to the lower magnitude observed in the range of $4.9-6.2 \mathrm{~Hz}$ in $N$-nitroso-3-benzyl derivatives 5-8.

Molecular mechanics calculations of several $\mathrm{N}$-nitroso-trans-3-alkyl-cis-2, 6-diphenylpiperidin4-ones ${ }^{7}$ have shown that the boat form $\mathbf{B}_{4}$ with alkyl group at flagpole position is having higher energy when compared to alternate chair form $\mathbf{C A}$ and boat 
forms $\mathbf{B}_{1}, \mathbf{B}_{2}$ and $\mathbf{B}_{5}$. Therefore in the present study, the boat conformation $\mathbf{B}_{4}$ is also neglected.

The trans and cis couplings about $\mathrm{C}(5)-\mathrm{C}(6)$ bond are expected to be around 10 and $4 \mathrm{~Hz}$ in boat form $\mathbf{B}_{1}$ and 4 and $10 \mathrm{~Hz}$ in boat form $\mathbf{B}_{5}$. However, both the trans and cis couplings are expected to be lower $(3-4 \mathrm{~Hz})$ in the boat conformation $\mathbf{B}_{2}$ and alternate chair form CA. The observed couplings in the range of $6 \cdot 6-7 \cdot 2$ and $3 \cdot 6-5 \cdot 3 \mathrm{~Hz}$ about $\mathrm{C}(5)-\mathrm{C}(6)$ bond in 5-8, suggest that these compounds cannot exist in single conformation. They may exist as an equilibrium mixture of two or more conformers in solution. The observed coupling around $7 \mathrm{~Hz}$ about $\mathrm{C}(5)$ $\mathrm{C}(6)$ bond indicates that the major conformer cannot be $\mathbf{B}_{2}$ and $\mathbf{C A}$. The major conformer may be either the boat form $\mathbf{B}_{1}$ or the boat form $\mathbf{B}_{5}$. In the boat form $\mathbf{B}_{5}$, syn 1,3-diaxial interaction exists between aryl rings at C-2 and C- 6 whereas this interaction does not exist in the boat form $\mathbf{B}_{1}$. Therefore, the major conformer may be $\mathbf{B}_{1}$. The observed coupling constants can be accounted for three possibilities: (i) an equilibrium mixture of $\mathbf{B}_{1}$ and $\mathbf{C A}$, (ii) an equilibrium mixture of $\mathbf{B}_{1}$ and $\mathbf{B}_{2}$ and (iii) an equilibrium mixture of $\mathbf{B}_{1}$ and $\mathbf{B}_{5}$.

In alternate chair form $\mathbf{C A}$ and boat form $\mathbf{B}_{5} s y n$ 1,3-diaxial interaction exists between aryl rings at C-2 and C- 6 and hence these forms are destabilized to some extent. However in boat form $\mathbf{B}_{2}$ such interaction is absent. Therefore, based on coupling constants it is suggested that the $\mathbf{Z}$ isomers of $N$-nitroso derivatives 5-8 exist as an equilibrium mixture of boat forms $\mathbf{B}_{1}$ and $\mathbf{B}_{2}$

The coupling constants about $\mathrm{C}(2)-\mathrm{C}(3)$ bond in the $\mathbf{E}$ isomers of $N$-nitroso-3-benzyl derivatives 5-8 are in the range of $1.3-1.9 \mathrm{~Hz}$. The two couplings observed about $\mathrm{C}(5)-\mathrm{C}(6)$ bond are in the range of $8 \cdot 5-10 \cdot 2$ and $6 \cdot 2-6 \cdot 8 \mathrm{~Hz}$. The coupling constants are in contrast to the values observed in piperidin-4ones 1-4 which exist in normal chair conformation with equatorial orientations of all the substituents. In order to relieve $\mathrm{A}^{1,3}$ strain, the $N$-nitroso derivatives 5-8 may adopt alternate chair form or boat form. The possible conformations for the $\mathbf{E}$ isomers of 5-8 are shown in scheme 3 .

In conformations $\mathbf{C E}, \mathbf{B}_{4}$ and $\mathbf{B}_{6}$ shown in scheme 3 , allylic strain exists between $N$-nitroso group and aryl ring at C- 6 and hence these conformations are ruled out in the present study. The conformations $\mathbf{B}_{2}$ and $\mathbf{B}_{3}$ are also not possible since in these conformations $J_{2,3}$ are expected to be around $10-12 \mathrm{~Hz}$ which is in contrast to the lower magnitude observed in the range of $1.3-1.9 \mathrm{~Hz}$ in $\mathrm{N}$-nitroso-3-benzyl deriva-

tives 5-8. The trans and cis couplings about $\mathrm{C}(5)-$ $\mathrm{C}(6)$ bond are expected to be around 10 and $4 \mathrm{~Hz}$ in boat form $\mathbf{B}_{1}$ and 4 and $10 \mathrm{~Hz}$ in boat form $\mathbf{B}_{5}$. However, both the trans and cis couplings are expected to be lower $(3-4 \mathrm{~Hz})$ in the alternate chair form CA. The observed couplings in the range of $8 \cdot 5-10 \cdot 2$ and $6 \cdot 2-6 \cdot 8 \mathrm{~Hz}$ about $\mathrm{C}(5)-\mathrm{C}(6)$ bond and $1.3-1.9 \mathrm{~Hz}$ about $\mathrm{C}(2)-\mathrm{C}(3)$ bond in $\mathbf{5 - 8}$, ruled out the possibility of existing in alternate chair form CA. The observed coupling constants can be accounted by either the highly distorted boat form $\mathbf{B}_{1}$ or the boat form $\mathbf{B}_{5}$. In the boat form $\mathbf{B}_{5}$ syn 1,3diaxial interaction exists between aryl rings at $\mathrm{C}-2$ and $\mathrm{C}-6$ whereas this interaction does not exist in the boat form $\mathbf{B}_{1}$. Therefore the $\mathbf{E}$ isomers of 5-8 exist in the highly distorted boat form $\mathbf{B}_{1}$. A small amount of boat form $\mathbf{B}_{5}$ to be equilibrium cannot be completely excluded in the present study.

3.1c Conformation of benzylic group at C(3) in 18: There are three possible conformations A, B and

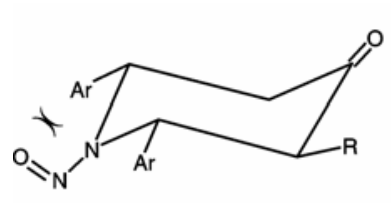

CE
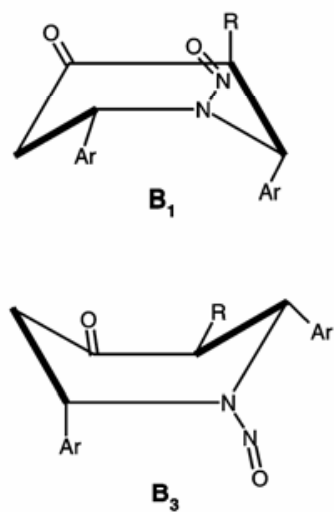

$\left(\mathrm{J}_{2,3}\right.$ large $)$

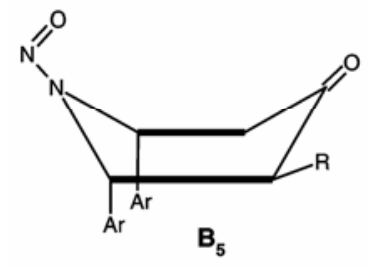

$$
\begin{aligned}
& \mathrm{R}=\mathrm{CH}_{2} \mathrm{Ph} \\
& \mathrm{Ar}=\mathrm{Ph}
\end{aligned}
$$

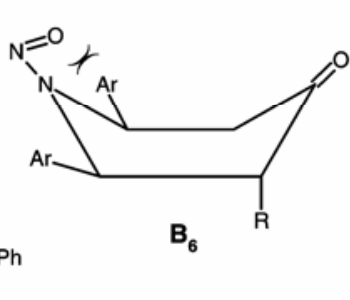

Scheme 3. Possible conformation of the $\mathbf{E}$-isomers of

5-8.
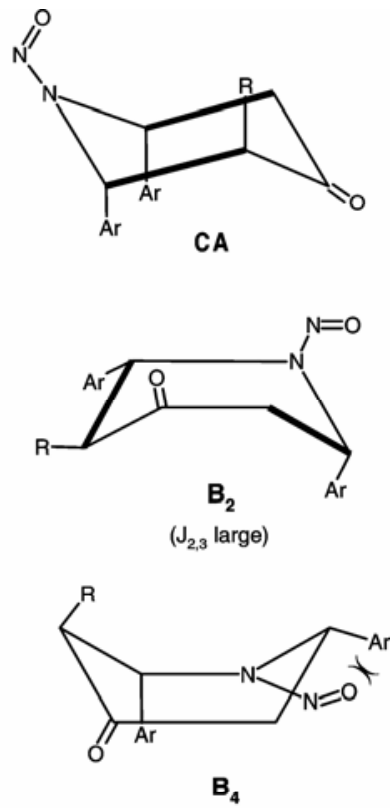
C for the benzylic group at C-3 in 1-4 as shown in figure 2. In conformation $\mathbf{C}, \mathrm{H}(3)$ is gauche with respect to both the methylene protons of the benzylic group at $\mathrm{C}-3$ and hence both the coupling constants $J_{\mathrm{H}(3), \mathrm{CH} 2 \mathrm{Ph}}$ are expected to be around $3-4 \mathrm{~Hz}$. However, in conformations $\mathbf{A}$ and $\mathbf{B}$, one coupling is expected to be around $10-12 \mathrm{~Hz}$ and other coupling is expected to be around 3-4 Hz. In piperidin-4-ones 1-4 the coupling constants extracted are around 3 and $8 \mathrm{~Hz}$. The former corresponds to gauche coupling and other value falls in between those for a gauche and anti coupling. This large coupling suggests that the major conformer may be either $\mathbf{A}$ or $\mathbf{B}$. Moreover in the conformation $\mathbf{C}$, two gauche interactions exist (phenyl with $\mathrm{C}(2)$ and $C(4)$ substituents) whereas in the other forms $\mathbf{A}$ and $\mathbf{B}$ only one gauche interaction (phenyl with either $\mathrm{C}-2$ or $\mathrm{C}-4$ substituents) is present. Drieding model reveals that in conformation $\mathbf{B}$, there will be severe interaction between phenyl ring of the benzylic group at $\mathrm{C}-3$ with the aryl ring at C-2 and hence this conformation is ruled out in the present study. Therefore, the favoured conformation of benzylic group at C-3 in the piperidin-4-ones 1-4 is predicted to be A. In conformation $\mathbf{A}$ the large and small couplings are expected to be 10 and $3 \mathrm{~Hz}$. However, the observed couplings 8 and $3 \mathrm{~Hz}$ suggest that a small amount of another conformer, i.e. the conformation $\mathbf{B}$ may also be present in solution in addition to the major conformation A. Among the methylene protons of the<smiles>CC1C(C)C2C(C)C(C)C1C[C@@H]2c1ccccc1</smiles>

A

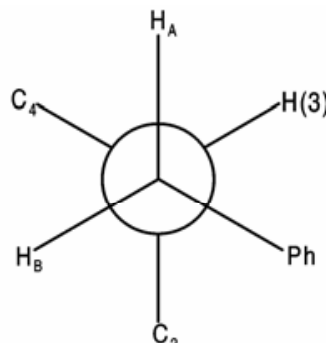

B<smiles>CC1C(C)C(C)C([Hg])C1C</smiles>

C
Figure 2. Possible conformations of benzylic group at $\mathrm{C}(3)$ in $\mathbf{1 - 4}$. benzylic group at $\mathrm{C}-3$, the one that experiences large coupling with $\mathrm{H}(3)$ in conformer $\mathbf{A}$ experience small coupling with $\mathrm{H}(3)$ in conformer $\mathbf{B}$ and vice versa. Thus, the conformation of benzylic group in the piperidin-4-ones 1-4 is found to be an equilibrium mixture of conformers A (major) and $\mathbf{B}$ (minor). In $\mathrm{N}$-nitroso-3-benzyl derivatives 5-8 also one can have three conformations $\mathbf{A}^{\prime}, \mathbf{B}^{\prime}$ and $\mathbf{C}^{\prime}$ (figure 3 ). For the $\mathbf{E}$ isomer the coupling constants extracted are around 4 and $10 \mathrm{~Hz}$. The former corresponds to gauche coupling and other corresponds to anti coupling. These couplings ruled out the possibility of existing in the conformation $\mathbf{C}^{\prime}$ and suggest that the favourable conformer may be either $\mathbf{A}^{\prime}$ or $\mathbf{B}^{\prime}$. Moreover in the conformation $\mathbf{C}^{\prime}$, two gauche interactions exists whereas in the other forms $\mathbf{A}^{\prime}$ and $\mathbf{B}^{\prime}$ only one gauche interaction is present. Drieding model reveals that in conformation $\mathbf{B}^{\prime}$, there will be more interaction between phenyl ring of the benzylic group at C-3 with the aryl ring at C-2 and hence this conformation is ruled out in the present study. Therefore, the favoured conformation of benzylic group at $\mathbf{C}-3$ in the $\mathbf{E}$ isomers of $\mathbf{5 - 8}$ is predicted to be $\mathbf{A}^{\prime}$.

In the $\mathbf{Z}$ isomers of $N$-nitroso-3-benzyl derivatives 5-8, the coupling constants extracted are around 5 and $7 \mathrm{~Hz}$. The former corresponds to gauche coupling and other value falls in between those for a

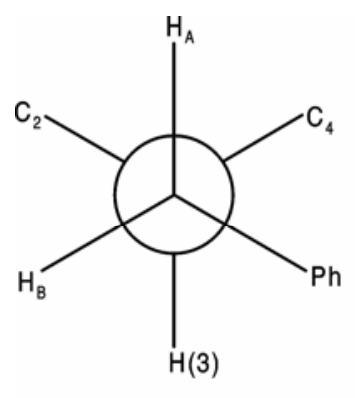

$A^{\prime}$

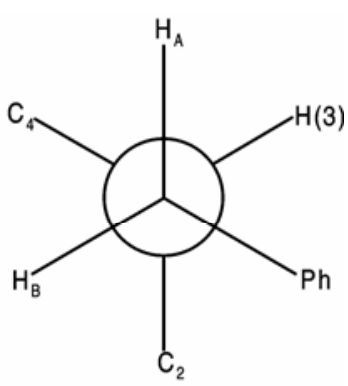

B' $^{\prime}$

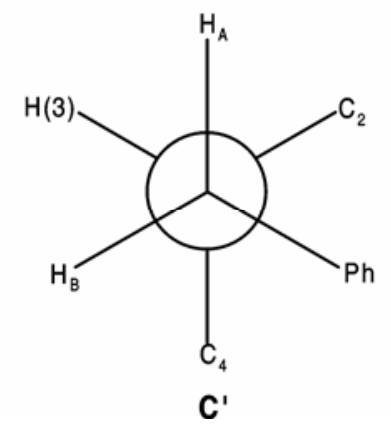

Figure 3. Possible conformations of benzylic group at $\mathrm{C}(3)$ in 5-8. 
Table 3. Observed ${ }^{1} \mathrm{H}$ deshielding magnitude (ppm)* in $N$-nitrosopiperidin-4-ones 5-8.

\begin{tabular}{|c|c|c|c|c|c|c|}
\hline \multicolumn{2}{|c|}{ Compound } & $\mathrm{H}(2)$ & $\mathrm{H}(3)$ & $\mathrm{H}(5)$ & $\mathrm{H}(6)$ & $\mathrm{CH}_{2} \mathrm{Ph}$ \\
\hline 5 & $\begin{array}{l}\mathbf{E} \\
\mathbf{Z}\end{array}$ & $\begin{array}{l}+2.59 \\
+2.33\end{array}$ & $\begin{array}{l}+(0.66-0.55) \\
+(0.43-0 \cdot 31)\end{array}$ & $\begin{array}{l}+0 \cdot 34,+0 \cdot 34 \\
+0 \cdot 75,+0 \cdot 62\end{array}$ & $\begin{array}{l}+1 \cdot 74 \\
+2 \cdot 40\end{array}$ & $\begin{array}{l}-0.30 \text { to }-0.41,+0.80 \\
-0.09 \text { to }-0.20,+0 \cdot 38\end{array}$ \\
\hline 6 & $\begin{array}{l}\mathbf{E} \\
\mathbf{Z}\end{array}$ & $\begin{array}{l}+2.49 \\
+2.27\end{array}$ & $\begin{array}{l}+(0 \cdot 62-0.50) \\
+(0 \cdot 37-0 \cdot 31)\end{array}$ & $\begin{array}{l}+0 \cdot 27,+0 \cdot 22 \\
+(0 \cdot 64-0 \cdot 70),+(0 \cdot 50-0 \cdot 56)\end{array}$ & $\begin{array}{l}+1.77 \\
+2.36\end{array}$ & $\begin{array}{l}-0.29 \text { to }-0.41,0.75-0.81 \\
-0.26 \text { to }-0.38,+0.53\end{array}$ \\
\hline 7 & $\begin{array}{l}\mathbf{E} \\
\mathbf{Z}\end{array}$ & $\begin{array}{l}+2.50 \\
+2 \cdot 25\end{array}$ & $\begin{array}{l}+(0.57-0 \cdot 60) \\
+(0 \cdot 35-0 \cdot 40)\end{array}$ & $\begin{array}{l}+0 \cdot 29,+0 \cdot 20 \\
+(0 \cdot 64-0 \cdot 69),+(0 \cdot 49-0.54)\end{array}$ & $\begin{array}{l}+1.77 \\
+2.38\end{array}$ & $\begin{array}{l}0 \text { to }-0 \cdot 05,+0 \cdot 33 \\
-0 \cdot 25,+0 \cdot 36\end{array}$ \\
\hline 8 & $\begin{array}{l}\mathbf{E} \\
\mathbf{Z}\end{array}$ & $\begin{array}{l}+2.54 \\
+2.44\end{array}$ & $\begin{array}{l}+(0 \cdot 57-0 \cdot 59) \\
+(0 \cdot 42-0 \cdot 40)\end{array}$ & $\begin{array}{l}+0 \cdot 31,+0 \cdot 24 \\
+0 \cdot 64,+0 \cdot 57\end{array}$ & $\begin{array}{l}+1.93 \\
+2.44\end{array}$ & $\begin{array}{l}-0 \cdot 02,+(0 \cdot 30-0 \cdot 36) \\
-0 \cdot 21,+(0 \cdot 30-0 \cdot 36)\end{array}$ \\
\hline
\end{tabular}

*Calculated relative to compounds $\mathbf{1 - 4}$.

Table 4. Observed ${ }^{13} \mathrm{C}$ shielding and deshielding magnitude (ppm)* in $N$ nitrosopiperidin- 4-ones 5-8.

\begin{tabular}{|c|c|c|c|c|c|c|c|}
\hline \multicolumn{2}{|c|}{ Compound } & $\mathrm{C}(2)$ & $\mathrm{C}(3)$ & $\mathrm{C}(4)$ & $C(5)$ & $C(6)$ & $\mathrm{CH}_{2} \mathrm{Ph}$ \\
\hline 5 & $\begin{array}{l}\mathbf{E} \\
\mathbf{Z}\end{array}$ & $\begin{array}{r}-5 \cdot 17 \\
-11.48\end{array}$ & $\begin{array}{l}-6.98 \\
-6 \cdot 37\end{array}$ & $\begin{array}{l}-0.82 \\
-1.04\end{array}$ & $\begin{array}{l}-7.92 \\
-9.01\end{array}$ & $\begin{array}{l}-6 \cdot 38 \\
-1 \cdot 23\end{array}$ & $\begin{array}{l}+5.42 \\
+4 \cdot 32\end{array}$ \\
\hline 6 & $\begin{array}{l}\mathbf{E} \\
\mathbf{Z}\end{array}$ & $\begin{array}{r}-4.98 \\
-11.64\end{array}$ & $\begin{array}{l}-6 \cdot 57 \\
-5 \cdot 80\end{array}$ & $\begin{array}{l}-1.03 \\
-1.26\end{array}$ & $\begin{array}{c}-8.59 \\
-10 \cdot 04\end{array}$ & $\begin{array}{l}-6 \cdot 25 \\
-1 \cdot 33\end{array}$ & $\begin{array}{l}+5.16 \\
+4.09\end{array}$ \\
\hline 7 & $\begin{array}{l}\mathbf{E} \\
\mathbf{Z}\end{array}$ & $\begin{array}{r}-5.64 \\
-11.89\end{array}$ & $\begin{array}{l}-7 \cdot 16 \\
-6 \cdot 14\end{array}$ & $\begin{array}{l}-1.73 \\
-1.93\end{array}$ & $\begin{array}{c}-9 \cdot 31 \\
-10 \cdot 23\end{array}$ & $\begin{array}{l}-6 \cdot 83 \\
-1.96\end{array}$ & $\begin{array}{l}+4.76 \\
+3.46\end{array}$ \\
\hline 8 & $\begin{array}{l}\mathbf{E} \\
\mathbf{Z}\end{array}$ & $\begin{array}{r}-5.07 \\
-12.40 \\
\end{array}$ & $\begin{array}{l}-7 \cdot 63 \\
-7 \cdot 10 \\
\end{array}$ & $\begin{array}{l}-0.50 \\
-0.50 \\
\end{array}$ & $\begin{array}{l}-8.79 \\
-9.56 \\
\end{array}$ & $\begin{array}{l}-7.85 \\
-1.09 \\
\end{array}$ & $\begin{array}{l}+5.72 \\
+4.87 \\
\end{array}$ \\
\hline
\end{tabular}

*Calculated relative to compounds $1-4$

gauche and anti coupling. This large coupling suggests that the major conformer may be either $\mathbf{A}^{\prime}$ or $\mathbf{B}^{\prime}$. Based on the arguments given for the $\mathbf{E}$ isomers, the major conformation of benzylic group at $\mathrm{C}-3$ is predicted to be $\mathbf{A}^{\prime}$ in the $\mathbf{Z}$ isomers also. The large and small couplings observed around 7 and $5 \mathrm{~Hz}$ suggest that a small amount of another conformer, i.e. the conformation $\mathbf{B}^{\prime}$ may also be present in solution in addition to the major conformation $\mathbf{A}^{\prime}$. Thus the conformation of benzylic group in the $\mathbf{Z}$ isomers of 5-8 is found to be an equilibrium mixture of conformers $\mathbf{A}^{\prime}$ (major) and $\mathbf{B}$ (minor).

\subsection{Analysis of chemical shifts}

Comparison of the chemical shifts of $N$-nitroso derivatives 5-8 with those of the corresponding piperidin-4-ones 1-4 reveal that the replacement of $-\mathrm{NH}$ by $-\mathrm{N}-\mathrm{N}=\mathrm{O}$ group deshields most of the heterocyclic ring protons and the observed deshielding magnitude are displayed in table 3 . The magnitude of deshielding observed on the syn $\alpha$ protons, i.e. $\mathrm{H}(2)$ in the $\mathbf{Z}$ isomer and $\mathrm{H}(6)$ in the $\mathbf{E}$ isomer ranges from +1.7 to $2.4 \mathrm{ppm}$ and this is closer to the values observed for syn $\alpha$-equatorial protons which lie in the same plane of the N-NO moiety. Moreover, the deshielding magnitude observed on anti $\alpha$ protons [H(2) in the $\mathbf{E}$ isomer; $\mathbf{H}(6)$ in the $\mathbf{Z}$ isomer] is also higher [ +2.59 to $2.36 \mathrm{ppm}]$ compared to the anti $\alpha$ axial protons in the normal chair conformation. Thus, the observed deshielding of $\alpha$ protons are inconsistent with the normal chair conformation $\mathbf{C E}$ thus supporting conformations in which syn $\alpha$ protons lie in the same plane of the $\mathrm{N}-\mathrm{N}=\mathrm{O}$ moiety.

The observed deshielding magnitude of $\mathrm{H}(3)$ and $\mathrm{H}(5)$ protons in $N$-nitroso derivatives 5-8 due to $\mathrm{N}$-nitrosation is probably due to the change in conformation, i.e. an equilibrium mixture of boat forms $\mathbf{B}_{1}$ and $\mathbf{B}_{2}$ for $\mathbf{Z}$ isomers of 5-8 and $\mathbf{E}$ isomer of 5-8 the boat conformation $\mathbf{B}_{1}$ only. 
Table 4 reveals that the shielding values observed on syn $\alpha$ carbons $[\mathbf{C}(6)$ in $\mathbf{E}$ isomer and $\mathbf{C}(2)$ in $\mathbf{Z}$ isomer] are considerably higher than the values observed in normal chair conformation CE. However, the magnitude of shielding observed on anti $\alpha$ carbons [C(2) in $\mathbf{E}$ isomer and $\mathbf{C}(6)$ in the $\mathbf{Z}$ isomer] are lower than the values observed in normal chair conformation $\mathbf{C E}$. The magnitude of shielding observed on $\beta$ carbons, i.e. $\mathrm{C}(3)$ is considerably lower than those observed on $\mathrm{C}(5)$ indicating different configurations of benzylic groups at $\mathrm{C}(3)$ in 5-8 compared to the corresponding piperidin-4-ones 1-4. All these values support other than normal chair conformation for 5-8, i.e. conformation in which syn $\alpha$ hydrogens lie in the same plane of $\mathrm{N}-\mathrm{NO}$ moiety.

In conclusion, the conformations of $\mathbf{Z}$ isomers of $N$-nitroso-t(3)-benzyl-r(2), c(6)-bis(aryl)piperidin-4ones 5-8 are established to be an equilibrium mixture of boat forms $\mathbf{B}_{1}$ and $\mathbf{B}_{2}$ by ${ }^{1} \mathrm{H}$ and ${ }^{13} \mathrm{C}$ spectral studies and the $\mathbf{E}$ isomers of 5-8 exist in boat conformation $\mathbf{B}_{1}$ only.

\section{Acknowledgement}

The authors thank the University Grants Commission (UGC), New Delhi for support through a major research project.

\section{References}

1. Albright J D, Delos Santos E G, Dusza J P, Chan P S, Coupet J, Ru X and Mazandarani H 2000 Bioorg. Med. Chem. Lett. 10695

2. (a) Pandiarajan $\mathrm{K}$, Manimekalai $\mathrm{A}$ and Kalaiselvi $\mathrm{N}$ 1997 Magn. Reson. Chem. 35 372; (b) Bhavani N, Natarajan D and Manimekalai A 2000 Indian J. Chem. B39 16

3. Harris R K and Spragg R A 1969 J. Mol. Spectrosc. 3077

4. (a) Krishnakumar R and Krishnapillay M 1996 Indian J. Chem. B35 418; (b) Krishnapillay M, Krishnakumar R, Nagarajan A and Jeyaraman R 2000 Indian J. Chem. B39 419

5. Ravindran T, Jeyaraman R, Murray R W and Singh M 1991 J. Org. Chem. 564833

6. Gdaniec M, Milewska M J and Po-lonski T $1995 \mathrm{~J}$. Org. Chem. 607411

7. Vijayalakshmi R, Muthukumar M, Ponnusamy S and Jeyaraman R 2006 Indian J. Chem. B45 2720

8. Senthilkumar U P, Jeyaraman R, Murray R W and Singh M 1992 J. Org. Chem. 576006

9. Jeyaraman R, Senthilkumar U P and Bigler P $1995 \mathrm{~J}$. Org. Chem. 607461

10. Natarajan D, Bhavani N and Manimekalai A 1997 Magn. Reason. Chem. 35597

11. Ravindran T 1993 Synthesis, stereodynamics and reactivity of $N$-nitrosopiperidines and $N$-nitroso-3-azabicyclo [3.3.1] nonanes. Bharathidasan University, India

12. Priya V, Shamala N, Viswamitra M A, Ravindran $T$ and Jeyaraman R 1993 Acta. Crystallogr. C49 983

13. Thangamani A, Jayabharathi $\mathrm{J}$ and Manimekalai A 2009 J. Struct. Chem. 50628

14. Noller C R and Baliah V 1948 J. Am. Chem. Soc. 703853 